\title{
TRAFFIC NOISE MONITORING AT ROAD INTERSECTIONS IN URBAN SETTLEMENT: CASE STUDY OF RAMAT PARK BENIN CITY
}

\author{
E. S. Okonofua ${ }^{1}$, R. Ehigiator-Irughe ${ }^{2, *}$ and M. Ekun ${ }^{3}$ \\ 1,2,3 Department of Geomatics, Faculty of Environmental Sciences, University of Benin, Edo State, NiGERIA \\ E-mail addresses:1ehizonomhen.okonofua@uniben.edu2raphael.ehigiator@uniben.edu \\ 3 mercy.ekun@uniben.edu.ng
}

\begin{abstract}
Ramat Park is one of the popular Parks in Benin City which is in form of a roundabout connecting traffic from Benin City to the North and Central part of the state including Delta state. In most cases, especially on market days, there is a gridlock within the park which necessitates the uncontrolled honking of horns and emission of other vehicular noise in a bid to checkmate reckless driving. Traffic noise was measured within a period of one month using digital noise meter at $10 \mathrm{~m}$ away from the source of the noise and about $1.2 \mathrm{~m}$ above ground level. Two traffic models (Rahul Singh Equation and Calixto Model) were used to calculate the vehicular noise level and the values obtained correlated well with the observed values. The plots of the measured and computed noise levels gave Root Mean Squares (RMS) of 0.776 and 0.839respectively.This indicates that the pattern of the scattered plot is narrow and there is a strong relationship between both computed and measured noise. It was therefore concluded that indiscriminate and reckless activities of drivers (especially commercial bus drivers) were responsible for the noise emission while enforcement of traffic laws in the state and relocation of the motor park close to the square were recommended control measures for noise reduction.
\end{abstract}

Keywords: Traffic, Noise, Observed, Calculated, Noise Meter.

\section{INTRODUCTION}

One indicative parameter considered [1]; in delineating a geographical location as rural or urban is the number of vehicles plying the routes within the region on a daily basis. The movement of vehicular traffic is not without the attendant noise thus making urban settlements noise prone zones especially places with major road networks [2]. In order to ease the flow of traffic in cities, roundabouts are usually constructed but in recent times especially on market days, the traffic gridlock and its associated noise at Ramat Park has reached alarming proportion which if not addressed adequately will develop into a nightmare making the Park a no-go-area to motorists and other settlers thereby defeating the essence of constructing the square.

Apart from the fact that the level of vehicular traffic noise depend mainly on traffic volume, traffic speed and the number of heavy duty vehicles in the stream of traffic; indiscriminate parking of cars on roads and reckless activities of motorist also contribute immensely to the traffic noise at Ramat Park. Globally, vehicular traffic noise has been recognized as one of the main source of environmental pollution which has led to series of research and development of traffic noise models. Also, in advanced countries where tackling vehicular traffic noise is taken as a priority, a lot of models for traffic noise prediction have been developed. Most of these noise models were developed from fundamental quantities and some of which are; flow of traffic, vehicle speed and sound emission level using linear regression [3]. In order to control vehicular noise level at road intersections within urban settlement; it is of paramount importance that these noise predictive models be adopted [3, 4,].

On a typical day (between 7:30am -8:30am) driving through Ramat Park is stressful and the annoyance due to traffic noise pollution needs to be studied and properly documented. Prediction models for vehicular traffic especially at road intersection are an essential requirement for the design of roads and in 
evaluating of existing or expected variation in vehicular traffic noise prediction $[5,6]$. Constant exposure to this noise can affect human physical wellbeing in terms of sleep, hearing disability, disturbance in conversations and cardiovascular problems [7]. From the foregoing, it therefore becomes imperative to monitor and eventually develop prediction model for traffic noise within this location $[8,9]$. The main aim of the study is to monitor and develop a model for traffic noise prediction within the vicinity of Ramat Park.

\section{MATERIALS AND METHODS}

Ramat Park is surrounded by two dual carriage ways channeling traffic from Aduwawa and Agbor park into ring road and vice versa .Ramat Park is located at Ikopba Okha Local Government Council, Edo state and it lies within latitude $6021^{\prime} 4.47^{\prime \prime} \mathrm{N}$ to $6020^{\prime} 58.33^{\prime \prime} \mathrm{N}$ and longitude $5039^{\prime} 40.97^{\prime \prime} \mathrm{E}$ to $5039^{\prime} 41.82^{\prime \prime} \mathrm{E}$. The park was created in the 1980's by the then military administration of the state and was later named in memory of the late Head of State, Murtala Ramat Muhammad. The park was initially a relaxation spot with Olympic size swimming pool and other recreational facilities for kids. Presently, the park has been abandoned while reptiles and hoodlums have taken over the place for lack of maintenance. The main roundabout is over $300 \mathrm{~m}$ in perimeter and it receives traffic from King's Square, Benin-Auchi road and Benin-Agbor road. The commercial activities within and around the square coupled with the road network contributes immensely to the traffic noise experienced daily within the square. Noise within the study area is worse on market days as traders display their goods very close to the road making the carriage way to be very narrow. Pedestrian crossing and indiscriminate parking alongside stopping and picking of passengers contributes to the traffic gridlock and noise within the vicinity.

\subsection{DATA ACQUISITION}

Traffic Noise levels were measured at these roads at different hourly intervals irrespective of whether the traffic flow was mild, average or heavy. The time intervals adopted were: 6:30am - 9:30am, 10:30am $1: 30 \mathrm{pm}, 2: 30 \mathrm{pm}-5: 30 \mathrm{pm}$ and $6: 00 \mathrm{pm}-8: 00 \mathrm{pm}$ respectively. During the study, the nature of vehicular traffic, parking pattern and commercial activities within the study area was evaluated.

Vehicles plying the routes were counted manually within the time range indicated above. Traffic Noise measurements were carried out at two different locations (opposite Warri Park and front of Anambra super market) and the values summed to get the interval readings. Digital Noise meter was used to collect the traffic noise data at $1.5 \mathrm{~m}$ clearance from natural ground surface and $12 \mathrm{~m}$ away from the Noise source. The measurement was carried out for a period of 31 days (August 1st to 31st). Google Earth imagery was used to acquire satellite imagery of Ramat Park and its vicinity while calibrated Handheld GNSS receiver was used to acquire coordinate of the area of study. Details of vehicular traffic flow, speed of vehicle $(\mathrm{m} / \mathrm{s})$, percentage of heavy duty vehicles as well as Noise level emitted are presented in tables 1 and 2 respectively.

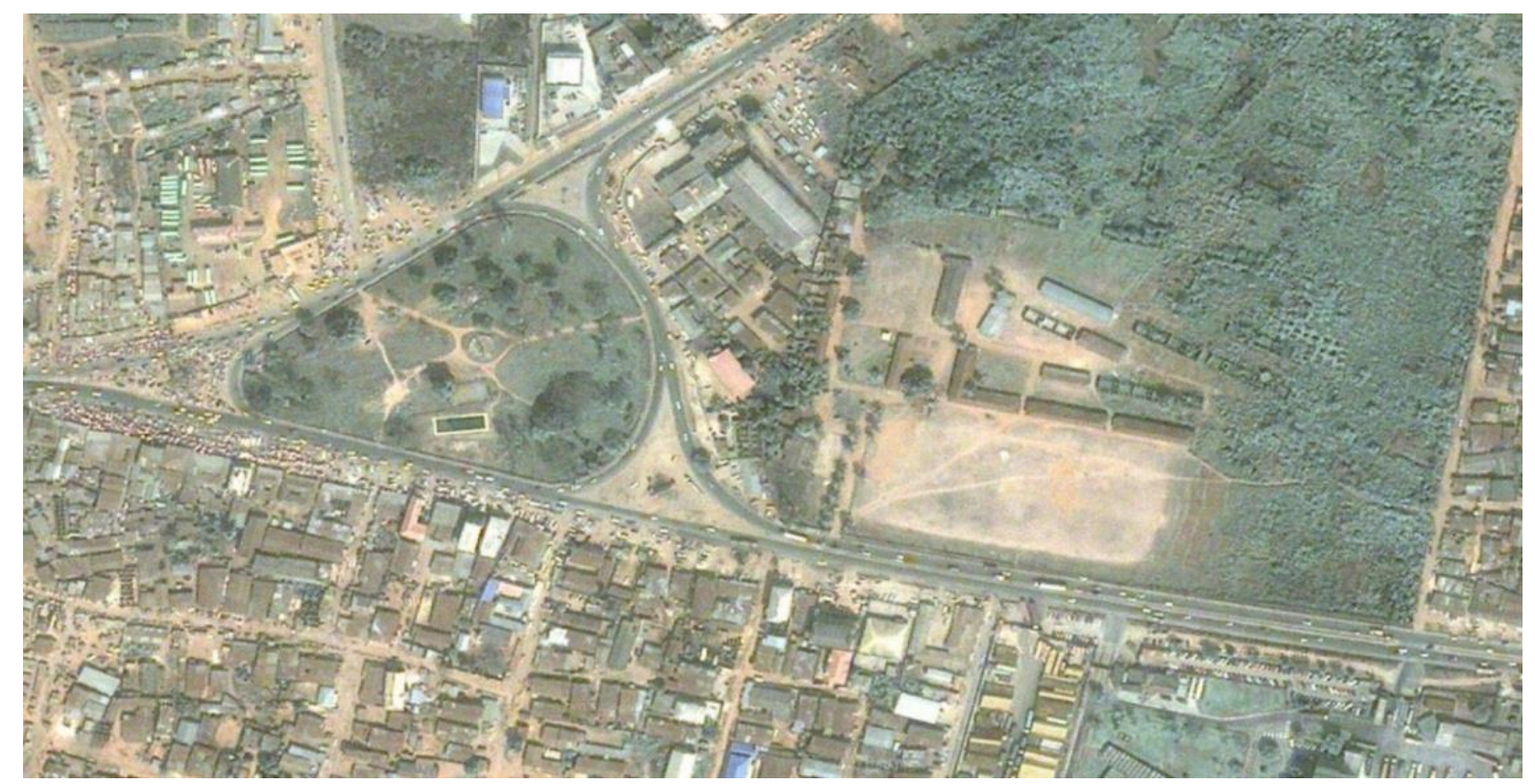

Figure 1: Google Imagery of Study Area 


\subsection{Empirical Prediction Model for Traffic Noise}

Traffic Noise level can be calculated by the application of Noise Level from previous study. The equation for the prediction of Traffic Noise level is given as eq. (1):

$$
\begin{aligned}
L_{-} c a l=10 \log Z & +33 \log \left(S+40+\frac{50}{S}\right) \\
& +10 \log \left(1+\frac{5 P_{v}}{S}\right)-26.6
\end{aligned}
$$

Where $\mathrm{Z}=$ volume of Traffic, $\mathrm{Pv}=$ percentage of heavy duty vehicles, $\mathrm{S}=$ mean vehicular speed $(\mathrm{km} / \mathrm{h})$.

Also, Calixto model which is used for noise modeling in developing countries was also used to model the observe noise data. The equation is given as eq. (2):

$$
\mathrm{Qeq}=\mathrm{Z}\left(1+\left(\mathrm{n} \times \frac{\mathrm{Pv}}{100}\right)\right)
$$

The expression 10log (Zeq) which is commonly used for noise computation was transformed into

$$
\begin{gathered}
\text { Qeq }=10 \log 19.92224\left\{\mathrm{Z}\left(1+\frac{\mathrm{n} \times \mathrm{Pv}}{100}\right)\right\} \\
+12.59764
\end{gathered}
$$

Weighting Factor, n, is always calculated as correlation coefficient between the observed noise values and the expression of equation 3 and $n$ was found to be 11 . This value was substituted into eq. 3 and used for further computations.

\section{PRESENTATION AND DISCUSSION OF RESULTS}

The results of the findings (observed and computed

\begin{tabular}{|c|c|c|c|c|c|c|c|c|c|}
\hline $\mathrm{S} / \mathrm{N}$ & & Noise Le & el $(\mathrm{dbA})$ & & $\begin{array}{c}\text { Average } \\
\text { Observed } \\
\text { Noise Level } \\
\text { (dbA) }\end{array}$ & $\begin{array}{l}\text { Volume of } \\
\text { vehicles } \\
\text { (Z) }\end{array}$ & $\begin{array}{c}\text { Mean } \\
\text { Speed of } \\
\text { vehicle } \\
(\mathrm{km} / \mathrm{h}), \mathrm{S}\end{array}$ & $\begin{array}{c}\text { Percentage of } \\
\text { Heavy Duty } \\
\text { Vehicle }\left(\mathrm{P}_{\mathrm{v}}\right)\end{array}$ & $\begin{array}{l}\text { Computed } \\
\text { Noise } \\
\text { Level dbA }\end{array}$ \\
\hline & $\begin{array}{l}\text { 6:30am- } \\
9: 30 \mathrm{am}\end{array}$ & $\begin{array}{l}10: 30 \mathrm{am}- \\
1: 30 \mathrm{pm}\end{array}$ & $\begin{array}{l}2: 30 \mathrm{pm}- \\
5: 30 \mathrm{pm}\end{array}$ & $\begin{array}{l}6: 00 \mathrm{pm}- \\
8: 00 \mathrm{pm}\end{array}$ & & & & & \\
\hline 1 & 65.11 & 74.02 & 69.19 & 70.30 & 69.66 & 762 & 53.28 & 7.04 & 69.569 \\
\hline 2 & 52.79 & 40.12 & 49.88 & 57.08 & 66.04 & 547 & 50.06 & 5.95 & 67.463 \\
\hline 3 & 82.64 & 77.43 & 71.03 & 86.71 & 79.45 & 950 & 67.90 & 8.81 & 72.536 \\
\hline 4 & 84.25 & 78.43 & 83.60 & 91.66 & 84.49 & 1074 & 71.66 & 10.1 & 73.696 \\
\hline 5 & 81.22 & 79.05 & 86.81 & 93.72 & 85.2 & 1363 & 73.04 & 9.82 & 74.821 \\
\hline 6 & 84.37 & 80.68 & 79.11 & 90.43 & 83.65 & 1055 & 70.12 & 12.53 & 73.879 \\
\hline 7 & 87.97 & 79.61 & 82.91 & 92.44 & 85.73 & 1209 & 75.48 & 11.74 & 74.868 \\
\hline 8 & 72.02 & 67.93 & 74.81 & 78.07 & 73.21 & 959 & 65.69 & 8.44 & 72.269 \\
\hline 9 & 82.52 & 77.62 & 81.06 & 90.62 & 82.96 & 1007 & 72.82 & 9.94 & 73.506 \\
\hline 10 & 93.71 & 88.29 & 78.91 & 88.29 & 87.3 & 1482 & 75.03 & 10.33 & 75.473 \\
\hline 11 & 91.07 & 73.61 & 82.21 & 88.38 & 83.82 & 1094 & 70.74 & 9.83 & 73.635 \\
\hline 12 & 82.52 & 76.83 & 87.78 & 91.74 & 84.72 & 1076 & 72.77 & 11.37 & 74.035 \\
\hline 13 & 88.81 & 77.73 & 77.01 & 90.90 & 83.61 & 1099 & 70.14 & 9.72 & 73.573 \\
\hline 14 & 84.57 & 78.06 & 81.06 & 94.27 & 84.49 & 1141 & 72.07 & 11.4 & 74.225 \\
\hline 15 & 69.93 & 72.39 & 80.49 & 91.73 & 78.64 & 984 & 69.65 & 9.03 & 72.914 \\
\hline 16 & 93.23 & 79.82 & 82.77 & 90.80 & 86.66 & 994 & 74.05 & 12.92 & 74.067 \\
\hline 17 & 89.52 & 80.63 & 80.76 & 91.21 & 85.53 & 1107 & 75.55 & 12.00 & 74.533 \\
\hline 18 & 91.87 & 79.07 & 80.10 & 89.74 & 85.2 & 1304 & 76.03 & 10.76 & 75.088 \\
\hline 19 & 90.52 & 76.82 & 84.22 & 90.66 & 85.56 & 1293 & 75.92 & 9.96 & 75.947 \\
\hline 20 & 89.08 & 90.72 & 83.14 & 92.04 & 88.75 & 1402 & 76.89 & 13.5 & 75.920 \\
\hline 21 & 90.72 & 88.91 & 81.19 & 91.41 & 88.06 & 1382 & 77.01 & 12.9 & 75.778 \\
\hline 22 & 61.43 & 84.21 & 82.44 & 88.53 & 79.15 & 1049 & 69.56 & 10.22 & 73.402 \\
\hline 23 & 83.73 & 86.46 & 85.73 & 90.05 & 86.49 & 1192 & 74.54 & 12.12 & 74.776 \\
\hline 24 & 91.84 & 87.98 & 86.07 & 92.71 & 89.65 & 1503 & 77.06 & 13.54 & 76.244 \\
\hline 25 & 87.38 & 75.66 & 87.5 & 91.07 & 85.4 & 1473 & 76.83 & 11.45 & 75.809 \\
\hline 26 & 81.16 & 81.06 & 79.00 & 92.70 & 83.48 & 1184 & 70.44 & 10.53 & 74.073 \\
\hline 27 & 94.77 & 80.49 & 81.63 & 90.0 & 86.72 & 1273 & 76.59 & 10.95 & 75.070 \\
\hline 28 & 87.96 & 82.77 & 84.77 & 93.80 & 93.33 & 1484 & 77.61 & 12.55 & 83.101 \\
\hline 29 & 63.52 & 76.93 & 83.71 & 92.75 & 79.23 & 1088 & 68.80 & 12.41 & 73.862 \\
\hline 30 & 72.08 & 84.62 & 88.29 & 84.25 & 82.31 & 1118 & 67.83 & 11.54 & 73.736 \\
\hline 31 & 95.44 & 89.88 & 88.38 & 81.22 & 69.66 & 1553 & 76.08 & 12.4 & 76.118 \\
\hline
\end{tabular}
Noise Levels) are presented in Tables 1 and 2. Figure 1 shows the bar chart of the observe and computed Noise Levels respectively.

Table 1: Measurement of Noise level (dB A) and Traffic Parameters Using Rahul Singh Equation 
Table 2: Measurement of Noise level (dB A) and Traffic Parameters Using Calixto Model

\begin{tabular}{|c|c|c|c|c|}
\hline S/NO. & $\begin{array}{c}\text { Total No. of } \\
\text { Vehicles/hour (Z) }\end{array}$ & $\begin{array}{c}\text { Percentage of Heavy Vehicles } \\
\left(\mathrm{P}_{\mathrm{v}}\right)\end{array}$ & Mean Observed Noise & Calculated Noise \\
\hline 1. & 762 & 7.04 & 69.66 & 74.624 \\
\hline 2. & 547 & 5.95 & 49.97 & 71.184 \\
\hline 3. & 950 & 8.81 & 79.45 & 77.387 \\
\hline 4. & 1074 & 10.1 & 84.49 & 79.022 \\
\hline 5. & 1363 & 9.82 & 85.20 & 80.963 \\
\hline 6. & 1055 & 12.53 & 83.65 & 79.855 \\
\hline 7. & 1209 & 11.74 & 85.73 & 80.725 \\
\hline 8. & 959 & 8.44 & 73.21 & 77.297 \\
\hline 9. & 1007 & 9.94 & 82.96 & 78.396 \\
\hline 10. & 1482 & 10.33 & 87.30 & 81.907 \\
\hline 11. & 1094 & 9.83 & 83.82 & 79.065 \\
\hline 12. & 1076 & 11.37 & 84.72 & 79.569 \\
\hline 13. & 1099 & 9.72 & 83.61 & 79.056 \\
\hline 14. & 1141 & 11.4 & 84.49 & 80.088 \\
\hline 15. & 984 & 9.03 & 78.64 & 77.792 \\
\hline 16. & 994 & 12.92 & 86.66 & 79.489 \\
\hline 17. & 1107 & 12.00 & 85.53 & 80.066 \\
\hline 18. & 1304 & 10.76 & 85.20 & 80.981 \\
\hline 19. & 1293 & 9.96 & 85.56 & 80.568 \\
\hline 20. & 1402 & 13.5 & 88.75 & 82.680 \\
\hline 21. & 1382 & 12.9 & 88.06 & 82.332 \\
\hline 22. & 1049 & 10.22 & 79.15 & 78.870 \\
\hline 23. & 1192 & 12.12 & 86.49 & 80.753 \\
\hline 24. & 1503 & 13.54 & 89.65 & 83.297 \\
\hline 25. & 1473 & 11.45 & 85.40 & 82.318 \\
\hline 26. & 1184 & 10.53 & 83.48 & 80.049 \\
\hline 27. & 1273 & 10.95 & 86.72 & 80.851 \\
\hline 28. & 1484 & 12.55 & 87.33 & 82.815 \\
\hline 29. & 1088 & 12.41 & 79.23 & 80.076 \\
\hline 30. & 1118 & 11.54 & 82.31 & 79.968 \\
\hline 31. & 1553 & 12.4 & 88.73 & 83.151 \\
\hline
\end{tabular}

\section{RESULT VALIDATION}

The calculated noise level using equations 1 and 3 were compared with the observed noise and the plots are presented in figure 1 and 2 above. The Root Mean Square values derived from both plots are: $r^{2}=0.776$ and 0.839 respectively; this shows that the pattern of the scattered is narrow and there is a strong linear relationship between traffic noise calculated and traffic noise observed. The value of 1.0 is considered to be the best fit, but any value above 0.7 is also considered to be good.

The value of ' $t$ ' (unpaired t-test distribution) is used to test whether the deviations of two processes are significant or not. It is also used to test how well a set of observations fit a given distribution. It therefore, provides a test of goodness of fit. To test the significance of discrepancy between observed and calculated traffic noise levels we have applied test of goodness of fit. It enables us to know whether deviation of measured from calculated is not by chance but due to inadequacy of the theory to fit measured data [7]. Table 3 shows the validity of the results obtained from the study.

Table 3: Result Validity Table for 60 degree of freedom and $\mathrm{t}_{\text {calculated }}=11.217$

\begin{tabular}{ccc}
\hline $\mathrm{S} / \mathrm{N}$ & Level of Significance & $\mathrm{t}_{\text {tabulated }}$ \\
\hline 1 & 0.05 & 2.000 \\
2 & 0.1 & 1.671 \\
3 & 0.5 & 0.679 \\
\hline
\end{tabular}

Table 4: Noise Risk Zones

\begin{tabular}{ll}
\hline Intensity of Noise, $\mathrm{dB}(\mathrm{A})$ & Category of Zones \\
\hline$<66$ & Safe \\
$66-71$ & Tolerable \\
$71-76$ & Low Risk \\
$76-81$ & Moderate Risk \\
$81-86$ & High Risk \\
$>86$ & Extremely High Risk \\
\hline
\end{tabular}
Source: [10]

\section{CONCLUSION AND RECOMMENDATION}

Traffic noise observed at Ramat Park was found to be above day time standard recommended by Environmental Protection Agency (see Table 4).

Vol. 35, No. 4, 2016 


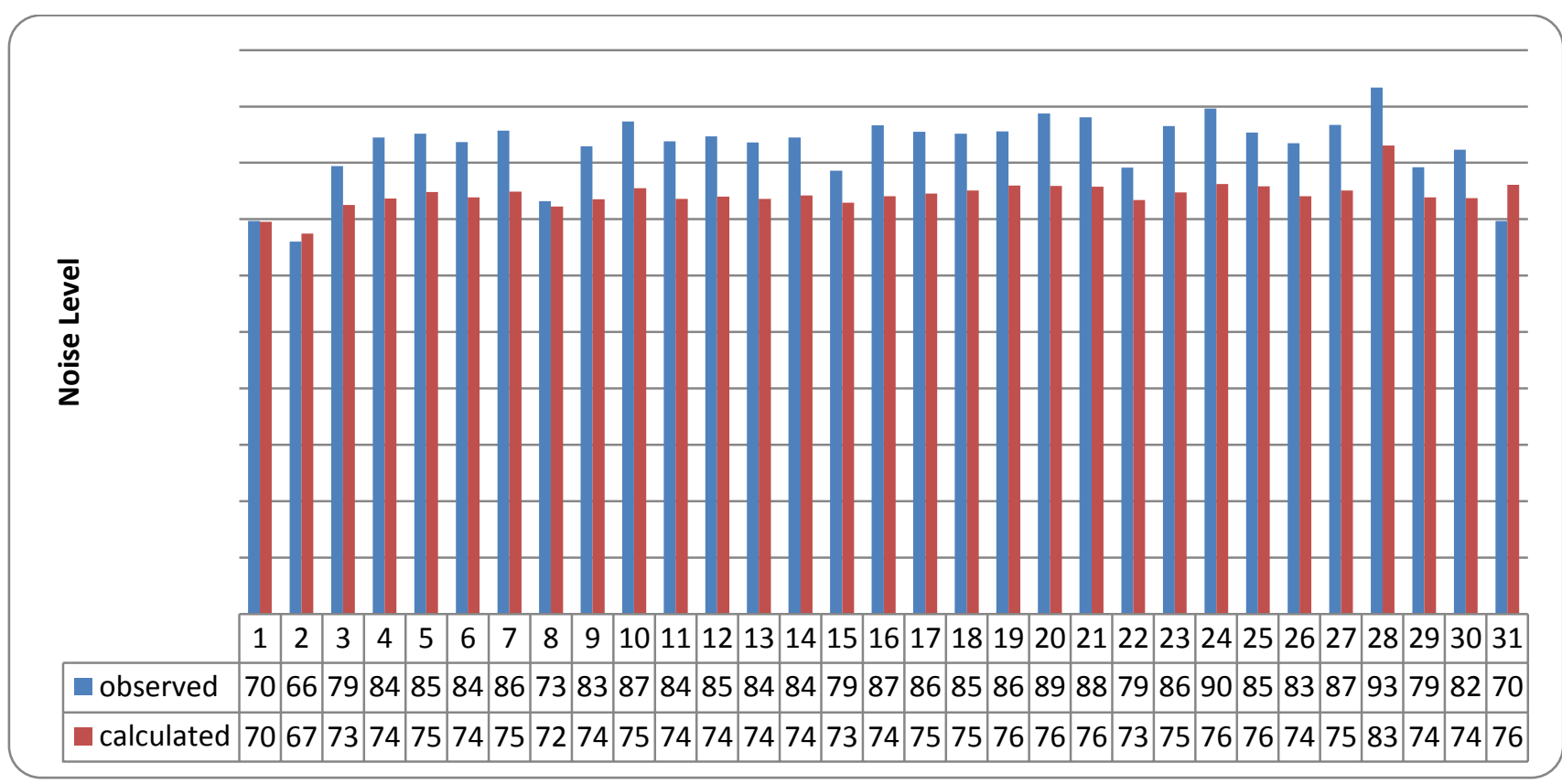

Figure 3: Bar Chart of Observed Noise Level d B(A) against calculated Noise Level dB(A)

Annoyance due to road traffic noise was found to be higher especially in the evenings and mornings which are generally referred to as rush hours. People living or undertaking commercial activities within Ramat Park are daily exposed to high levels of traffic noise which is as a result of indiscriminate and reckless activities of drivers within the Park and also the increased number of honking and horning couple with the high volume of vehicles congesting the area. The resultant effects of this environmental hazard are stress, sleeplessness and psychological effects.

Since traffic noise can be calculated from the volume of traffic, it is recommended that traffic barrier should be constructed to mitigate the traffic noise level. Improved traffic management practices, proper control of commercial buses (possibly bus park at the roundabout should be removed or relocated).

\section{REFERENCES}

[1] Selander, J. Nilsson, M. E., Bluhm, G. Rosenlund, M., Lindqvist, M. Nise G., Pershagen G., Long-term exposure to road traffic noise and myocardial infarction, Epidemiology, Vol. 20 No.2 pp 272-278. (2009).

[2] Golmohammadi R., Abbaspour M., Nassiri P., and Mahjub H. "Road Traffic Noise Model", J. Res health. Sci. Vol. 7 No. 1, pp. 13 - 17 (2007).

[2]. Golmohammadi R., Abbaspour M., Nassiri P., and Mahjub H.,: "Road Traffic Noise Model". J. Res health Sci. Vol 7, No 1, pp. 13 -17, (2007).
[3]. Guarnaccia C., Analysis of Traffic Noise in a Road Intersection Configuration, WSEAS Transactions on Systems, Issue 8, Volume 9, pp.865-874, ISSN: 1109-2777. (2010).

[4]. Stefano R. D. and Morri B., (2001): A Statistical Model for Predicting Road Traffic Noise on Poisson Type Traffic Flow. Noise control Eng J. 49(3):13743.

[5]. Onuu M. U and Menkiti A. I., Spectral Analysis of Road Traffic Noise in Some Parts of South Eastern Nigeria. Nigeria J. Phys. 15. [PROVIDE PAGE RANGE]. (1993).

[6]. Kumar K. and Jain V. K Autoregressive Integrated Moving Averages (ARIMA) Modeling of a Traffic Noise Time Series. Applies Acoustics 58 (3), pp. 283-294. (1999):.

[7]. Kumar K., Katiyar V. K., Parida M. and Rawat K.,: "Mathematically Modeling of Road Traffic Noise Prediction".International Journal of Applied Mathematics and Mech. 7(4): 21-28, 2011. (2011).

[8]. Okonofua E. S, and Ehigiator R. "Traffic Noise Analysis at Gridlocks within Road Intersections, Case Study of King Square Benin City" published at the Journal of Production Engineers Vol. 20, March 2016, pp 160 - 169.

[9]. Ali H.,: Measurement and Analysis of Noise Levels in Kaduna metropolis. PhD. Thesis, Nigerian Defense Academy Kaduna, Nigeria. (2010).

[10]. Banerjee, D., Chakraborty, K. S., Bhattacharyya, S., Gangopadhyay, A., Evaluation and analysis of road traffic noise in Asansol: An Industrial Town of Eastern India. Int. J. Environ. Res. Public Health, Vol.5. No.3, pp.165-171. (2008). 